Doorgapershad $M \&$ Bauling $H$

\title{
THE IMPACT OF GESTALT PLAY TECHNIQUES ON THE AGGRESSION LEVEL OF DIABETIC CHILDREN
}

\author{
M Doorgapershad, MA (SW) Play Therapy Student, University of Pretoria; H Bauling, Lecturer in \\ Department of Social Work, University of Pretoria.
}

\begin{abstract}
The study was undertaken to investigate the impact of gestalt group work play techniques on the aggression levels of diabetic children between the ages of 8 and 12 years. The motivation for the study developed from the researcher's interaction at the out-patient clinic at Addington Hospital, where staff indicated a need for group work sessions with patients at the juvenile diabetic clinic. The health team who managed the children also encountered the aggression. These two aspects offered an opportunity for the researcher to investigate the effect of gestalt group work play techniques on the aggression levels of these children. The sample consisted of two boys and two girls who attended the diabetic out-patient clinic at Parklands Hospital. The researcher selected gestalt group work play techniques to assist with decreasing the aggression levels of juvenile diabetics as the group situation allowed support and security for the group members who experimented with new behaviours. A comparison of pre-test and post-test results of respondents suggest a strong recommendation for inclusion of gestalt group work play techniques in the management of juvenile diabetics. The researcher is of the opinion that the aim of the study was successfully achieved and inclusion of gestalt group work play techniques be recommended as part of the holistic treatment of juvenile diabetics.
\end{abstract}

\section{INTRODUCTION}

This article is an overview of a research study that was part qualitative and part quantitative in nature. The study was undertaken to investigate the impact of gestalt group work play techniques on the aggression levels of diabetic children between the ages of 8 and 12 years. The sample consisted of two boys and two girls who attended the diabetic out-patient clinic at Parklands Hospital.

\section{MOTIVATION FOR THE STUDY}

The motivation for the study developed from the researcher's interaction at the diabetic out-patient clinic at Addington Hospital, where staff indicated a need for group work sessions with patients at the juvenile diabetic clinic. Discussions with staff revealed that there were an increasing number of false results from patients, as well as complaints from the parents regarding the aggression levels of these diabetic children. The health team who managed the children also encountered aggression. These two aspects offered an opportunity for the researcher to investigate the effects of gestalt group work play techniques and their effects on the aggression levels of these children. Studies focusing on aggression in diabetic children emphasised a positive relationship between aggression and the illness; however, there was no direction as to how this aggression can be managed in the diabetic child. This was highlighted in a comparative study between asthmatic children and diabetic children done by Nelms (1989:657-668). It was found that in his study both groups of children showed empathy, emotional responsiveness and depression. In a study done by Court, Sein, McCowen, Hackett \& Parkin (1988:16), the behaviour of 127 children with diabetes mellitus aged 8 to 16 years were assessed by their parents and teachers, using a well-established 
screening device and compared to that of 51 non-diabetic children. Twenty-five percent of the diabetic children were perceived by their parents to be disturbed, compared to only $14 \%$ of the controls. The above-mentioned researchers state that if the effects that the disease has on life style and the complex nature of the condition are considered, it is not surprising that diabetic children have behavioural and educational problems (Court et al. 1988:16).

The researcher utilised group work as a method of intervention, as it allowed the children an inside look into their illness, while drawing on support from the other children who have the disease. This approach allowed the children to offer solutions regarding coping mechanisms and alternatives to each other within a safe environment and helped them to see that there are peers who are experiencing the same problems associated with the disease.

The goals of the study were to investigate the impact of gestalt play techniques on the aggression level of diabetic children. The researcher aimed to achieve the following objectives:

- To conduct literature studies on the impact of juvenile diabetes on the child and gestalt group work play techniques;

- To do an empirical study to investigate the impact of gestalt group work techniques on the aggression levels of children with diabetes;

- To make recommendations on the use of these play techniques regarding the holistic treatment of diabetic children.

The hypothesis for the study was the following: if gestalt play techniques were utilised in therapy with diabetic children, there would be a decrease in aggression, rebelliousness and a better understanding of the illness.

\section{METHODOLOGY}

The single systems design was utilised to attain the goals and verify the hypothesis for the study within this framework. Gestalt play techniques were utilised for effective outcomes. The single systems design consists of repeated collection of information on a single system over time.

\section{LITERATURE STUDY - JUVENILE DIABETES MELLITUS (TYPE 1)}

Insulin-dependent diabetes mellitus (IDDM), also known as type 1 or juvenile diabetes, is a chronic life-long disorder involving consistent teaching and support from the relevant professionals (Hillson, 1996:29). Hillson's point clearly emphasises that juvenile diabetes is an illness that requires a multi-disciplinary team approach. Yousef (1993:29) supports the above view, stating that, in addition to its impact upon physical development, this condition may have various effects on psychological and behavioural development.

\section{DEFINITION OF MEDICAL CONCEPTS}

Yousef (1993:29) defines the relevant medical concepts as follows:

\section{Ketoacidosis}

Ketoacidosis occurs when the body starts to break down muscle tissue to produce energy for the body. This results in ketones being present in the blood. 


\section{Hyperglycaemia}

Hyperglycaemia is an increase of blood glucose. There are many different factors that can influence blood glucose levels. They could be hereditary, environmental or hormonal.

\section{Polyuria}

Polyuria is the production of large amounts of urine.

\section{Polydipsia}

Polydipsia is the consumption of large amounts of liquids.

\section{Polyphagia}

Polyphagia is the consumption of large amounts of food.

\section{JUVENILE (TYPE 1) DIABETES - ONSET}

Bloom (1980:11-12) states that individuals diagnosed with type 1 diabetes usually exhibit the following characteristics. This type of diabetes starts most commonly in children or young adults, but it may occur at any age, often in the very elderly. It is characterised by the rapid onset of symptoms, especially thirst (polydipsia), polyuria and lassitude. There is considerable loss of weight and most diabetics of this type are underweight at diagnosis. According to Fajan (1996:252), who also supports this view, the affected patient experiences an abrupt symptomatic onset of disease secondary to severe insulin deficiency (polyphagia, weight loss and fatigue), is prone to ketosis and is thin. Occasionally, however, type 1 diabetes can occur in the overweight. Diabetes can be categorised into primary and secondary diabetes. Primary diabetes has its beginnings in juveniles, where the onset is unknown, in adult life (maturity onset), where it is referred to as type 1 diabetes and the cause is also unknown; finally, it is associated with other genetic disorders, where the individual is susceptible to developing the illness. The common trait in all three is that the onset and cause are unknown. Secondary diabetes can be introduced into the body by surgery, disease, drugs or auto-immunity.

\section{TREATMENT AND DIETARY MANAGEMENT OF THE ILLNESS}

According to Bloom (1986:30), knowledge of four aspects of the disease is imperative in treatment and should be taught to children:

- How to draw and inject insulin - most children over the age of 6 or 7 should be able to inject themselves;

- What the diet is and especially which foods are carbohydrates and how much can be taken at each meal;

- When and how to test the urine or blood for sugar;

- To recognise hypoglycaemic reactions, to know what is likely to bring them on and to take sugar in good time.

The main rule to observe when one is diabetic is that one needs to lose weight if one is overweight. The diet, according to Hillson (1996:48), is divided into three types of food categories: carbohydrates, fat and protein. In diabetes, however, the most important component is carbohydrates. These carbohydrates need to contain a good deal of roughage and fibre. Jones 
(1998:115) also emphasises the distribution of meals during the day in amounts to balance the effects of injected insulin.

\section{PSYCHO-SOCIAL ISSUES RELATED TO JUVENILE DIABETES}

In the researcher's opinion there are multiple assessment issues relevant to the treatment of children with diabetes. Chronic illnesses such as diabetes require the patient to manage the disease on a daily basis. According to Ollendick (1998:422) and Lorenz (1985:875, 876), the most consistent findings are the inadequacy of patient knowledge, whether the patients are children or adults.

Cleaver (1994:272) states in her study that over-protectiveness in families did not promote independence, resulting in the children withdrawing, their boundaries shrinking and horizons narrowing. Feelings that the family associated with a relative who had diabetes and died as a result may be displaced onto the child in the present. This erroneous family thinking could lead to overprotection and smothering (Cleaver, 1994:272).

Diagnosis of chronic illness triggers the bereavement process in a parent; there may be much selfblame, especially if a parent has the disease. One should also take note that financial aspects of management might also represent major sources of stress for parents, which could stem from frequent admissions, mandatory check-ups and purchasing of insulin.

Children with diabetes often feel damaged. Cleaver's (1994:270) study on diabetes mellitus and its chronic effects on children found that the pronouncement of the diagnosis posed an even greater threat to the existence of the subjects. Her study further revealed that feelings of fear, uncertainty, vulnerability and hopelessness were reinforced amongst her subjects. The researcher is also of the opinion that greater collaboration between the different health teams needs to occur so that holistic and effective management of the juvenile diabetic can be achieved.

\section{LITERATURE STUDY - GROUP WORK PLAY TECHNIQUES AND GESTALT}

According to Schniebel (1991:3), gestalt is a German word that has no exact equivalent in English. The closest one can come to translating gestalt is wholeness, configuration or completeness of form. This phenomenological existential therapy founded by Fredrick Fritz and Laura Perls in the 1940s teaches therapists and patients that the phenomenological method of awareness in perceiving, feeling and acting are distinguished from interpreting and reshuffling pre-existing attitudes. Gestalt therapy offers an approach encouraging the therapist to be direct and active with clients, while at the same time encouraging concentration on the clients' own present experience of himself/herself.

Congress (1995:1118-1120) identified four types of dysfunctional boundary disturbances:

\section{Confluence}

Confluence means a client pretends that there are no differences between two individuals or systems.

\section{Introjection}

Introjection involves the incomplete assimilation of information from the environment. 


\section{Projection}

Projection is a result of individuals experiencing significant losses of important parts of their personalities by disowning them and projecting them onto others.

\section{Retroflection}

Retroflection occurs when individuals do to themselves what they would like to do to someone else, or when they do to themselves what they would like others to do to them.

The layers of neuroses or modes of defence are also an important aspect of focus within the confines of gestalt therapy. These include the following: phoney layer, phobic layer, impasse layer, implosive layer and explosive layer. The identification of where the client is with regards to these layers assists the gestalt therapist in identifying the level of behaviour awareness of the client. Corey (1990:318) states that by individuals re-experiencing past conflicts as if they were occurring in the present, clients expand their level of awareness, sometimes gradually and sometimes explosively. They are then able to face and integrate denied and fragmented parts of themselves, thus becoming unified and whole.

\section{EMPIRICAL STUDY}

To implement the empirical study projective techniques within the gestalt framework were utilised. These techniques were used to assist the researcher in assessing the effects on the variables that were being measured in the study. These variables were anger, rebellion, understanding of the illness, fear of diabetes and situations of conflict. Data from the group sessions were tabulated to facilitate understanding of the results. Session one focused specifically on completion of pre-test questionnaires with no therapeutic intervention. The themes of the group sessions were as follows:

\section{Group session two:}

Establishment of group rules and clarification of individual goals within the group. Session two was terminated by means of progressive body relaxation exercises.

\section{Group session three:}

The awareness continuum assessment. Drawing was utilised as a means of assessment. Oaklander's fourteen-step model was utilised to gain insight into the feelings that were projected on the drawings. Respondents were nurtured with the aid of a fantasy flight to ensure that heightened emotions were dealt with before termination of the session.

\section{Group session four:}

The awareness continuum assessment. Respondents were requested to draw the monster in their life. The feelings projected onto the monster was then dealt with by the use of clay and this medium allowed safe ventilation of aggressive feelings.

Group session five:

Session five was a continuation of session four. The same procedure of projection of aggression was utilised.

\section{Group session six:}

The purpose of this session was to increase the respondent's awareness and understanding of the illness. The awareness continuums of the respondents were once again assessed. It is felt that continual assessment of sensory modalities alert the researcher to any abnormalities that may 
occur with the senses. Biblio-therapy was the medium that was utilised with the story telling technique.

\section{Group session seven:}

Externalisation of rebellion was the purpose of session seven. The awareness continuum of the respondents was again assessed. Creative play in one medium was utilised. Respondents were requested in the previous session to bring along any materials that they would like to build their diabetic monster with.

\section{Group session eight:}

The completion of the diabetic monster occurred in this session. The awareness continuum of respondents was assessed. Respondents were requested to write their feelings towards the monster on the sheet that the monster was constructed on. Conflict resolution was also done with the respondents.

\section{Group session nine:}

The purpose of the session was to teach respondents to release their anger in a non-threatening way. The model of Scott (1990:37) was utilised to achieve this end. Respondents were reminded that the next session would be the final session. However, the researcher asked respondents at the conclusion of previous sessions to mark off each session so that respondents were visually and mentally aware of the termination session. The post-test questionnaire was administered.

\section{Group session ten:}

Termination session. A party was arranged with the handing out of certificates of attendance to respondents.

\section{IDENTIFYING DETAILS AND PRE-TEST RESULTS OF RESPONDENTS}

\section{CHILD A:}

Child A is in Grade 7 and is 12 years old. Child A was diagnosed with juvenile diabetes at age 9 and was compliant on medication on joining the group. Child A had the following pre-test results: anger $80 \%$, rebellion $60 \%$, understanding of the illness $50 \%$, fear of the illness $50 \%$, situations of conflict $70 \%$.

\section{CHILD B:}

Child B is an 11-year-old and is in Grade 5. He was diagnosed as a diabetic when he was 4 years old and was compliant on medication on joining the group. Child B had the following pre-test results: anger $60 \%$, rebellion $50 \%$, understanding of the illness $60 \%$, fear of the illness $50 \%$, situations of conflict $70 \%$.

\section{CHILD C:}

Child $\mathrm{C}$ is a 13-year-old and is in Grade 7. She was diagnosed as a diabetic for the longest period, as compared to the other respondents. Child $\mathrm{C}$ was compliant on medication on joining the group. Child $\mathrm{C}$ had the following pre-test results on joining the group: anger $70 \%$, rebellion $70 \%$, understanding of the illness $30 \%$, fear of the illness $90 \%$, situations of conflict $70 \%$.

\section{CHILD D:}

Child D is a 12-year-old and is in Grade 6. He was diagnosed as diabetic when he was 9 years old. Child D was compliant on medication on joining the group. Child D was the quietest of the respondents and the most withdrawn. Child D had the following pre-test results on joining the 
group: anger $70 \%$, rebellion $60 \%$, understanding of the illness $40 \%$, fear of the illness $40 \%$, situations of conflict $60 \%$.

\section{RESEARCH FINDINGS}

\section{Pre- and Post-Test Results for Child A}

A comparison of pre- and post-test results for child A revealed the following: anger had decreased from $80 \%$ to $30 \%$, rebellion had decreased from $60 \%$ to $20 \%$, understanding of the illness had increased from $50 \%$ to $90 \%$, fear of the illness had decreased from $50 \%$ to $10 \%$ and situations of conflict had decreased from $70 \%$ to $40 \%$.

Child A's post-test results indicate that therapeutic work rendered in the sessions impacted positively on the child and her emotional development regarding the illness. A significant decrease in anger and rebellion was noted. This indicates further the successful attainment and mastery of the different layers of neuroses. The progression of the child from the phoney layer to the explosive within a controlled, therapeutic environment allowed safe and supportive guidance through the different layers. Gestalt group work techniques enabled the child to close gestalts regarding the illness, thus facilitating closure and organism control.

\section{Pre- and Post-Test Results for Child B}

A comparison of pre-test and post-test results for child B revealed the following: anger had decreased from $60 \%$ to $20 \%$, rebellion had decreased from $50 \%$ to $10 \%$, understanding of the illness had increased from $60 \%$ to $90 \%$, fear of the illness had decreased from $50 \%$ to $20 \%$ and situations of conflict had decreased from $70 \%$ to $30 \%$.

The post-test results for child B indicate that the therapeutic group process significantly affected anger and situations of conflict. The techniques allowed the child to progress through the different layers of neuroses and deal with unfinished business regarding the illness. The eventual attainment of the explosive layer by child B allowed the child to experience significantly fewer situations of conflict. The group sessions allowed child B to experiment with behaviour congruent with the presenting emotions. It allowed him to balance his polarities and face the difficulties that the illness presented.

\section{Pre- and Post-Test Results for Child C}

A comparison of pre- and post-test results for child $\mathrm{C}$ revealed the following: anger had decreased from $70 \%$ to $20 \%$, understanding of the illness had increased from $30 \%$ to $80 \%$, rebellion had decreased from $90 \%$ to $30 \%$ and situations of conflict had decreased from $70 \%$ to $40 \%$.

For child $\mathrm{C}$ gestalt group work techniques played a major role and assisted in her understanding of her anger about being a juvenile diabetic, as well as developing a better understanding of the illness. The sessions allowed the child to understand the effects on her physical and psychological well-being. The techniques assisted the child simultaneously with release and experience of her anger, thus showing a marked decrease in this aspect. The positive interaction of the child allowed her to progress through the different layers of neuroses and attain the explosive layer. The techniques allowed the child to achieve awareness regarding her anger towards the illness and the ways in which this anger hindered her development. The group sessions enabled the child to close gestalts relating to the illness. 


\section{Pre- and Post-Test Results for Child D}

A comparison of pre- and post-test results of child D revealed the following: anger had decreased from $70 \%$ to $20 \%$. Rebellion had decreased from $60 \%$ to $10 \%$, understanding of the illness increased from $40 \%$ to $90 \%$, fear of the illness had decreased from $80 \%$ to $10 \%$ and situations of conflict decreased from $60 \%$ to $20 \%$.

Child D showed marked improvements in all aspects of the variables. Gestalt group work provided a two-fold function for the child. It provided him with the necessary skills required to cope with the illness and increased his self-esteem and self-confidence. This conclusion is supported by his pre- and post-test results and his positive progressive development in the group. A study of his interaction within the group showed that he had developed from an introverted and withdrawn child to an individual who was confident and contributed significantly to the group process. Gestalt group work techniques facilitated the closing of open gestalts. The negative energy that was utilised for these open gestalts was converted to positive energy resulting in a stronger self.

\section{CONCLUSIONS}

The researcher, having implemented gestalt group work play techniques with the respondents, derived the following conclusions:

- Gestalt group work allowed group members to experience feelings that were related to the illness and were sealed off from awareness, thus facilitating closure regarding these feelings;

- Self-awareness, interaction and generation of new information allowed painful emotions to be shared among the group members;

- Gestalt group work combined with play therapy has the following effects on juvenile diabetes: decrease in rebellion, increase in their understanding of the illness, decrease in situations of conflict, decrease in anger and decrease in their fear of the illness;

- Play therapy is an excellent form of therapeutic intervention for effecting behaviour change in juvenile diabetics;

- Organism control in gestalt and the technique of integrating of polarities in play therapy allow the child to achieve a balanced view of the conflict situation;

- Gestalt group work contributes to facilitating the development of the group process and encourages trust, cohesion, understanding, acceptance and respect to emerge among the group members;

- Members were able to achieve closure on unfinished business relative to the illness.

\section{RECOMMENDATIONS}

On the basis of the literature and empirical study undertaken the researcher would like to recommend that:

- Behavioural and therapeutic intervention be included in the juvenile diabetic's treatment programme;

- $\quad$ Supportive groups be offered for the parents of juvenile diabetics;

- A social worker skilled in appropriate therapeutic intervention be assigned to the diabetic clinics of hospitals; 
- Gestalt play techniques and gestalt groups be integrated in the diabetic treatment programme at hospitals;

- Play therapy within a group setting should be utilised as a form of therapeutic intervention with juvenile diabetics.

\section{REFERENCES}

BLOOM, A 1980. A Colour Atlas of Diabetes. London: Wolfe Medical Publications.

BLOOM, A 1986. Life with diabetes. London: British Medical Association.

CLEAVER, G 1994. Diabetes Mellitus: Experiencing a chronic illness. South African Journal of Psychology, 24:263-277.

CONGRESS, P 1995. Gestalt. Encyclopedia of Social Work, 19:117-1124.

COREY, G 1990. Theory and practice of group counselling. California: Pacific Grove Publishers.

COURT, S; SEIN, E; McCOWEN, C; HACKETT, AF \& PARKIN, JM 1988. Children with Diabetes Mellitus: Perception of their behavioural problems by parents and teachers. Early Human Development, 16:245-252.

FAJAN, S 1996. Diabetes Mellitus: A fundamental and clinical text. Definition and classification of diabetes including maturity-onset diabetes of the young. Philadelphia: Lippincott-Raven Publishers.

HILLSON, R 1996. Practical diabetes care. Oxford: Oxford University Press.

JONES, EW 1998. An illustrated guide for the diabetic clinic. Malden, Mass.: Blackwell Science, Inc.

LORENZ, R 1985. Diet related knowledge, skill and adherence among children with Insulindependent Diabetes Mellitus. Journal of Paediatrics, 75:872-876.

NELMS, BC 1989. Emotional behaviours in chronically ill children. Journal of Abnormal Child Psychology, 17:657-668.

OLLENDICK, TH 1998. Handbook of Child Psychopathology. ( $3^{\text {rd }}$ ed) . New York: Plenum Press.

SCHNEIBEL, D 1991. Group counselling using the gestalt approach. (Unpublished MA thesis United States: University Unknown)

SCOTT, GG 1990. Resolving conflict: With others and within yourself. Oaklander, CA: New Harbinger.

YOUSEF, MS 1993. Meeting the counselling needs of children with diabetes. International Journal for the Advancement of Counselling, 16:29-36. 